Full Paper

\title{
Square-Wave Voltammetry of Cathodic Stripping Reactions. Diagnostic Criteria, Redox Kinetic Measurements, and Analytical Applications
}

\author{
Rubin Gulaboski, ${ }^{\mathrm{a}}$ Valentin Mirčeski, ${ }^{\text {b }}$ Šbojka Komorsky-Lovrićc, Milivoj Lovrićc \\ a Institut für Chemie und Biochemie, Ernst-Moritz-Arndt-Universität Greifswald, Soldmannstraße 23, \\ D-17489 Greifswald, Germany \\ b Institute of Chemistry, Faculty of Natural Sciences and Mathematics, "Sv. Kiril i Metodij” University, P.O. Box 162, \\ 1000 Skopje, Republic of Macedonia \\ c Center for Marine Research Zagreb, "Rudjer Boškovic" Institute, POB 180, Zagreb 10002, Croatia \\ *e-mail: valentin@iunona.pmf.ukim.edu.mk
}

Received: April 15, 2003

Final version: June 9, 2003

\begin{abstract}
A comparative study of different types of cathodic stripping reactions under conditions of square-wave voltammetry is presented. Cathodic stripping processes involving reactions of second order as well as reactions coupled by adsorption of the reacting ligand are analyzed The inherent parameters, controlling the overall voltammetric behavior of each cathodic stripping electrode reaction are derived. The criteria for qualitative distinguishing of each mechanism are established as well as a methodology for redox kinetic measurements is proposed. The influence of the parameters of the excitation signal on the properties of the voltammetric response is analyzed in order to find optimal conditions for analytical application. The theoretical results are illustrated by the experiments with a series of uracil derivatives.
\end{abstract}

Keywords: Square-wave voltammetry, Theoretical modelling, Quasireversible maximum, Kinetic measurements, Uraciles

\section{Introduction}

Cathodic stripping voltammetry is a well-known electroanalytical method that has been widely used for quantitative determination of electrochemically inactive species capable to create sparingly soluble compounds with the electrode material [1-3]. In the course of the accumulation period, the working electrode, e.g., a hanging mercury drop electrode (HMDE) or a silver electrode, is anodically polarized at a constant potential, yielding a thin film of an insoluble salt on its surface [4-6]. The film is subsequently stripped off from the electrode surface by a potential scan in the cathodic direction. Recently this methodology has been applied to study important biologically active compounds such as cadmium and zinc metalthioniens as well as some drugs $[7,8]$.

Different factors affect the sensitivity of the method, among which the applied technique in the course of the stripping step plays an important role. In the family of pulse techniques, square-wave voltammetry (SWV) is particularly appealing because of the fast scan rate, large amplitude, and the capability to discriminate against the capacity current $[9$, 10]. Moreover, this technique enables simultaneous inspection of both reduction and oxidation processes and hence provides an insight into the mechanism of the electrode reaction.

The theory of cathodic stripping processes under conditions of SWV has been initiated by Lovric et al. [11] considering the most simple reaction system in which a sparingly soluble compound is formed between mercuric ions and a divalent ligand that is dissolved in the electrolyte solution (Reaction I).

$\mathrm{Hg}_{(1)}+\mathrm{L}^{2-}(\mathrm{aq})=\mathrm{HgL}_{(\mathrm{s})}+2 \mathrm{e}^{-}$

In the case of monovalent ligand, the following redox reactions should be considered:

$\mathrm{Hg}_{(1)}+2 \mathrm{~L}_{(\mathrm{aq})}^{-} \rightleftharpoons \mathrm{HgL}_{2(\mathrm{~s})}+2 \mathrm{e}^{-}$

or

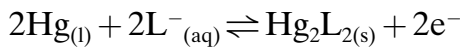

The latter mechanism is known as the cathodic stripping reaction of second order [12]. Numerous inorganic ions, such as halides [13-17], cyanide [18], thiosulfate and sulfite [19] as well as some of the sulfur containing organic compounds, such as miscellaneous thiols [20-25] and thioamides [26] react according to the Reaction II.

Furthermore, when an organic compound plays a role of a reacting ligand the cathodic stripping reaction could be additionally complicated by adsorption of the ligand. Thus both Reactions I and II could be transposed into the cathodic stripping reaction coupled by adsorption equilibrium of the ligand, i.e., the first order cathodic stripping 
reaction with adsorption of the ligand (Reaction III) and the second order reaction with adsorption of the ligand (Reaction IV).

$$
\begin{aligned}
& \mathrm{L}^{2-}{ }_{\text {(ads) }}+\mathrm{Hg}_{(\mathrm{l})} \rightleftharpoons \mathrm{HgL}_{(\mathrm{s})}+2 \mathrm{e}^{-} \\
& \uparrow \downarrow \\
& \mathrm{L}^{2-}{ }_{(\mathrm{aq})} \\
& 2 \mathrm{~L}^{-}{ }_{\text {(ads })}+\mathrm{Hg}_{(\mathrm{l})} \rightleftharpoons \mathrm{HgL}_{2(\mathrm{~s})}+2 \mathrm{e}^{-} \\
& \uparrow \downarrow \\
& 2 \mathrm{~L}^{-}{ }_{\text {(aq) }}
\end{aligned}
$$

or

$$
\begin{aligned}
& 2 \mathrm{~L}^{-}{ }_{\text {(ads) }}+2 \mathrm{Hg}_{(\mathrm{l})} \rightleftharpoons \mathrm{Hg}_{2} \mathrm{~L}_{2(\mathrm{~s})}+2 \mathrm{e}^{-} \\
& \uparrow \downarrow \\
& 2 \mathrm{~L}^{-}{ }_{\text {(aq) }}
\end{aligned}
$$

Experimental evidences for reaction mechanisms III and IV were already observed in the case of cystine [27], cysteine [28], 6-mercaptopurine [29], lyzozime [30], and different uracil derivatives [31-34].

In the present paper, utilizing the recently developed theoretical models $[11,12,33,34]$ a comparative analysis of all four electrode mechanisms under conditions of SWV is presented. The aim of the study is to establish simple diagnostic criteria for qualitative recognizing and distinguishing the type of the cathodic stripping reaction. Furthermore, the properties of the response that can be exploited for estimating the kinetic parameters of the reaction are discussed. Finally, the influence of parameters of the excitation signal on the sensitivity of the analytical method based on a respective cathodic stripping reaction is analyzed.

The theoretically predicted behavior of all cathodic stripping reactions will be experimentally illustrated studying the voltammetric response of the following uracile derivatives: 2-thiouracil (TU), 5-azauracil (AzaU), 5-fluorouracil (FU) [35], and 6-propyl-2-thiouracil (PTU) [33, 34]. Their general electrochemical behavior has been studied by means of classical DC and differential pulse polarography by Florence [3]. Although the basic voltammetric properties of FU and PTU under cathodic stripping mode are known [33-35], some of these results will be reused in the current paper for the sake of comparison with the other compounds.

\section{Experimental}

All used chemicals were of analytical reagent grade. PTU and FU were products of Henkel KG\&A Co. (Germany), while TU, and AzaU were products of Sigma-Aldrich (Germany), whereas all the other chemicals were purchased from "Merck". Water of MiliQ purity was used in all experiments. The stock solutions of all explored uracils were prepared by dissolving in an appropriate amount of methanol. Pure nitrogen was used for purging the electrolyte solutions for $8 \mathrm{~min}$ prior to each measurement. A nitrogen blanket, over the electrolyte solution, was maintained thereafter.

All voltammograms were recorded using the Autolab multimode polarograph (ECO Chemie, Utrecht, Netherlands) and polarographic analyzer PAR 384B combined with a static mercury drop electrode (SMDE) Model 303 A from Princeton Applied Research. A platinum wire was used as an auxiliary electrode and an $\mathrm{Ag} / \mathrm{AgCl}(3 \mathrm{~mol} / \mathrm{L}$ $\mathrm{KCl})$ was the reference. All the measurements were carried out at room temperature.

\section{Theoretical Models}

For all reactions it is assumed that the mass transport of the reacting ligand occurs through semi-infinitive planar diffusion. The mercury electrode surface is covered with a submonomolecular film of the sparingly soluble salt and there are no interactions between the deposited particles. For Reactions III and IV the ligand adsorption obeys the linear adsorption isotherm law. The general mathematical model is defined as follows:

$$
\begin{aligned}
& \frac{\partial c(\mathrm{~L})_{(x, t)}}{\partial t}=D \frac{\partial^{2} c(\mathrm{~L})_{(\mathrm{x}, \mathrm{t})}}{\partial x^{2}} \\
& t=0, x \geq 0: \quad c(\mathrm{~L})=c^{*}(\mathrm{~L}), \Gamma(\mathrm{HgL})=0 \\
& \text { (for Reactions I-IV) } \\
& \Gamma(\mathrm{L})=0 \quad(\text { for Reactions III and IV) } \\
& t>0, x \rightarrow \infty: c(\mathrm{~L}) \rightarrow c^{*}(\mathrm{~L}) \quad \text { (for Reactions I-IV) } \\
& t>0, x=0: \quad c(\mathrm{~L})_{x=0}=K_{\text {ads }} \Gamma(\mathrm{L}) \text { (for Reactions III and IV) }
\end{aligned}
$$

$$
\begin{aligned}
& D\left(\frac{\partial c(\mathrm{~L})_{(x, t)}}{\partial x}\right)_{x=0}=-\frac{I}{2 F S} \quad \text { (for Reactions I and II) } \\
& D\left(\frac{\partial c(\mathrm{~L})_{(x, t)}}{\partial x}\right)_{x=0}-\frac{\mathrm{d} \Gamma(\mathrm{L})}{\mathrm{d} t}=-\frac{I}{2 F S} \text { (for Reactions III and IV) }
\end{aligned}
$$

$$
\frac{\mathrm{d} \Gamma(\mathrm{HgL})}{\mathrm{d} t}=-\frac{I}{2 F S} \quad \text { (for Reactions I and III) }
$$$$
\frac{\mathrm{d} \Gamma\left(\mathrm{HgL}_{2}\right)}{\mathrm{d} t}=-\frac{I}{4 F S} \quad \text { (for Reactions II and IV) }
$$

$$
\frac{I}{2 F S}=k_{\mathrm{s}} \exp (-\alpha \varphi)\left(\frac{\Gamma(\mathrm{HgL})}{r_{\mathrm{s}}}-c(\mathrm{~L})_{(x=0)} \exp (\varphi)\right)
$$

$$
\frac{I}{2 F S}=k_{s} \exp (-\alpha \varphi)\left(\frac{\Gamma(\mathrm{HgL})}{r_{\mathrm{s}}}-\frac{\left(c(\mathrm{~L})_{(x=0)}\right)^{2}}{c_{\mathrm{s}}} \exp (\varphi)\right)
$$

(for Reactions II and IV)

(It is worth to point out that the equations describing Reactions II and IV hold equally for the Reactions IIa and 
Table 1. A list of symbols and abbreviations.

\begin{tabular}{|c|c|c|}
\hline Symbol & Meanings of the symbols and abbreviations & Units \\
\hline$\alpha$ & electron transfer coefficient & 1 \\
\hline$c$ & dimensionless concentration parameter & 1 \\
\hline$c^{*}(\mathrm{~L})$ & concentration of the reacting ligand in the bulk of the solution & $\mathrm{mol} \mathrm{cm} \mathrm{cm}^{-3}$ \\
\hline$c_{\mathrm{s}}$ & standard concentration & $1 \mathrm{~mol} \mathrm{~cm}^{-3}$ \\
\hline$D$ & diffusion coefficient of the ligand $\mathrm{L}$ & $\mathrm{cm}^{2} \mathrm{~s}^{-1}$ \\
\hline$\Delta E_{\mathrm{p} / 2}$ & half-peak width & $\mathrm{mV}$ \\
\hline$\Gamma(\mathrm{HgL})$ & surface concentration of the insoluble salt & $\mathrm{mol} \mathrm{cm} \mathrm{cm}^{-2}$ \\
\hline$\Gamma(\mathrm{L})$ & surface concentration of the adsorbed ligand & $\mathrm{mol} \mathrm{cm}^{-2}$ \\
\hline$E$ & potential & $\mathrm{V}$ \\
\hline$E_{\text {acc }}$ & accumulation potential & $\mathrm{V}$ \\
\hline$E_{\mathrm{p}}$ & square-wave peak potential & $\mathrm{V}$ \\
\hline$E_{\mathrm{sw}}$ & square-wave amplitude & $\mathrm{mV}$ \\
\hline$E^{\circ}$ & standard redox potential & V \\
\hline$f$ & square-wave frequency & $\mathrm{s}^{-1}$ \\
\hline$F$ & Faraday constant & $\mathrm{C} / \mathrm{mol}$ \\
\hline$\varphi$ & dimensionless potential & 1 \\
\hline$I$ & current & A \\
\hline$I_{\mathrm{p}}$ & peak current & A \\
\hline$k_{\mathrm{s}}$ & standard rate constant & $\mathrm{cm} \mathrm{s}^{-1}$ \\
\hline$K_{\text {ads }}$ & adsorption constant & $\mathrm{cm}^{-1}$ \\
\hline$R$ & gas constant & $\mathrm{J} \mathrm{mol}^{-1} \mathrm{~K}^{-1}$ \\
\hline$r_{\mathrm{s}}$ & auxiliary constant & $1 \mathrm{~cm}$ \\
\hline$\dot{S}$ & electrode surface area & $\mathrm{cm}^{2}$ \\
\hline$t$ & time & $\mathrm{s}$ \\
\hline$T$ & thermodynamic temperature & $\mathrm{K}$ \\
\hline$x$ & distance & $\mathrm{cm}$ \\
\hline$\Psi$ & dimensionless current & 1 \\
\hline$\Psi_{\mathrm{p}}$ & dimensionless peak current & 1 \\
\hline
\end{tabular}

IVa, while in both last cases (i.e. IIa and IVa) $a_{\mathrm{Hg}(1)}=1$, and $a^{2}$ $\mathrm{Hg}(1)=1)$. Here, $k_{\mathrm{s}}$ is the heterogeneous standard rate constant in units of $\mathrm{cm} \mathrm{s}^{-1}, r_{\mathrm{s}}$ and $c_{\mathrm{s}}$ are auxiliary constants defined as: $r_{\mathrm{s}}=1 \mathrm{~cm}$ and $c_{\mathrm{s}}=1 \mathrm{~mol} \mathrm{~cm} \mathrm{~cm}^{-3}$. The dimensionless potential is defined as $\varphi=2 F\left(E-E^{0}\right) / R T$. For the meaning of all other symbols see Table 1 .

The solutions of equation (1) corresponding to each cathodic stripping reaction have been obtained applying Laplace transform and the numerical method of Nicholson and Olmstead as described elsewhere [36]. The following theoretical results are expressed in a form of dimensionless current defined as: $\Psi=I /\left[2 F S c^{*}(L) \sqrt{D f}\right]$.

\section{Theoretical Results}

The theoretical dimensionless net SW voltammograms are bell-shaped curves, characterized with the peak potential $E_{\mathrm{p}}$, peak current $\Psi_{\mathrm{p}}$, and half-peak width $\Delta E_{\mathrm{p} / 2}$. A representative theoretical SW response of Reaction $\mathrm{I}$ is given in Figure 1A. The narrow forward (cathodic) component of the response depicts the reduction of the deposited salt $\mathrm{HgL}_{(\mathrm{s})}$, whereas the broad backward (anodic) component portraits the oxidation of mercury, controlled by the diffusion of the dissolved ligand. The response of Reaction I is predominantly controlled by the kinetic parameter $\lambda=k_{\mathrm{s}} /$
$\sqrt{D f}$, representing the charge transfer kinetics, and the diffusion parameter $\gamma=\sqrt{D} / r_{s} \sqrt{f}$, reflecting the diffusion of the ligand. The apparent reversibility depends on the complex kinetic parameter defined as $K=\lambda \sqrt{\gamma}$, or defined through the real parameters of the system as: $K=k_{\mathrm{s}} / D^{1 / 4} f^{3 / 4}$ $\sqrt{r_{s}}$. The intrinsic properties of Reaction I is the parabolic dependency of the dimensionless net peak current on the kinetic parameter $K$. Within the quasireversible region, the peak current increases dramatically reaching a maximum value for a certain critical value of the kinetic parameter $K_{\max }$. This property is known as "quasireversible maximum", which was thoroughly examined in our previous study [37]. The quasi-reversible maximum appears as a consequence of the current sampling procedure used in the SW voltammetry. When the frequency of the signal is synchronized with the charge transfer rate, a multiple re-use of the surface confined material occurs, producing a maximal response in the SW voltammetry. The importance of the quasireversible maximum steams from the fact that it serves for assessing the kinetic of electron transfer applying a simple experimental procedure that will be elaborated in the following section concerned with experimental results.

A representative SW voltammogram of Reaction II is shown in Figure 1B. In addition to the kinetic parameter $\lambda$ and diffusion parameter $\gamma$, the dimensionless response of Reaction II is controlled by the concentration parameter 

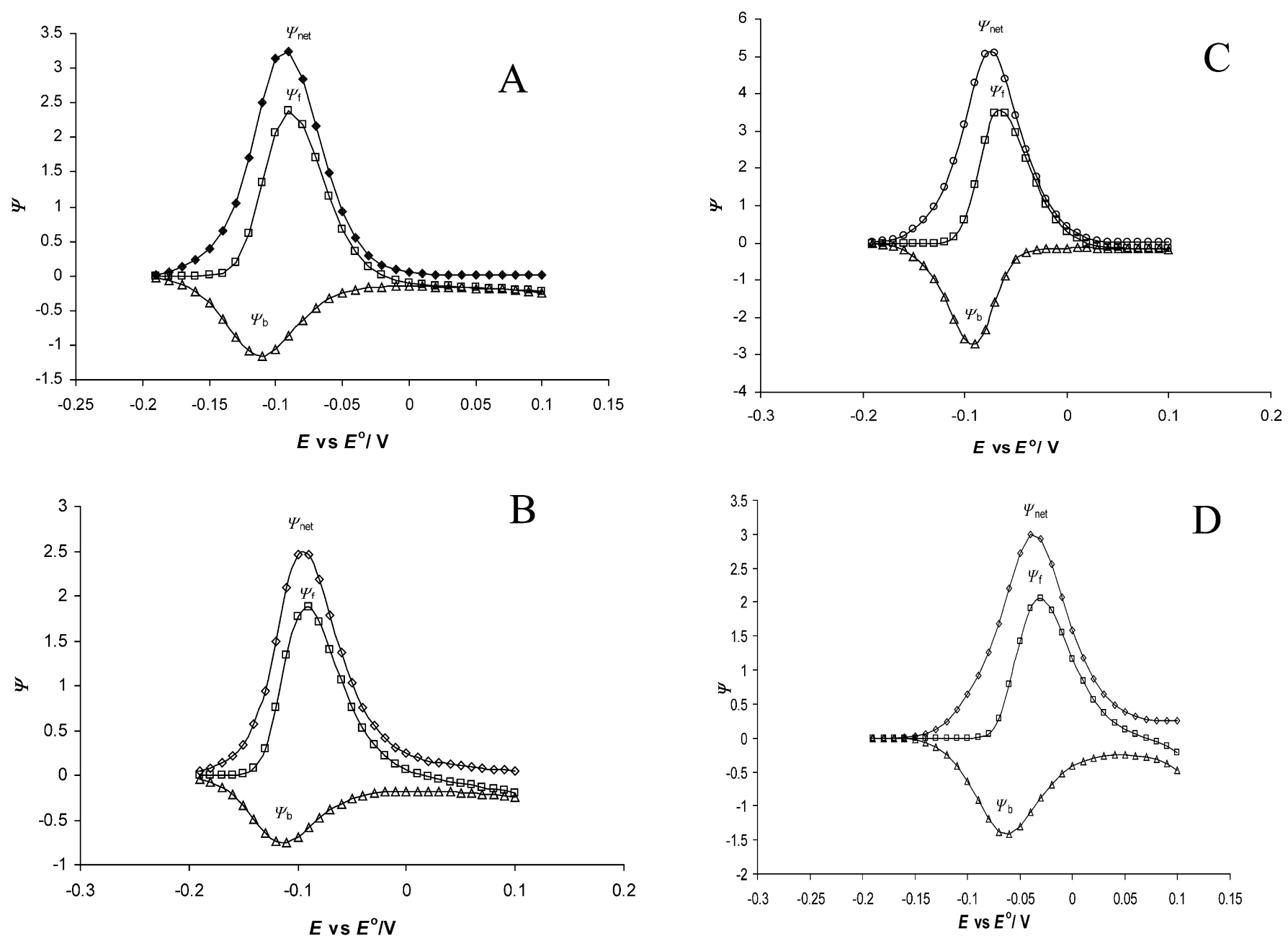

Fig. 1. Theoretical SW voltammograms of Reactions I (A), II (B), III (C), and IV (D). The conditions of the simulations were: $k_{\mathrm{s}}=10 \mathrm{~cm} \mathrm{~s}^{-1}$ (for A, B, and D) and $0.2 \mathrm{~cm} \mathrm{~s}^{-1}$ (for C), $\alpha=0.5, c=0.1$ (for B) and c $=0.001$ (for D), $K_{\text {ads }}=500 \mathrm{~cm}^{-1}$ (for C and D), $f=$ $10 \mathrm{~Hz}, E_{\mathrm{sw}}=50 \mathrm{mV}, \mathrm{d} E=10 \mathrm{mV}, E_{\mathrm{acc}}=0.1 \mathrm{mV}$, and $t_{\mathrm{acc}}=0.1 \mathrm{~s}$. The Symbols $\Psi_{\mathrm{f}}, \Psi_{\mathrm{b}}$, and $\Psi_{\text {net }}$ denote the forward, backward and net current, respectively.

defined as $c=c^{*}(\mathrm{~L}) / c_{\mathrm{s}}$, where $c^{*}(\mathrm{~L})$ is the bulk concentration of the ligand and $c_{\mathrm{s}}$ is the standard concentration. The concentration parameter produces major differences between the properties of Reactions I and II. The peak potential of Reaction II is sensitive to the ligand concentration, which is not the case for Reaction I. If Reaction II appears reversible, a linear dependence of $E_{\mathrm{p}} \mathrm{vs} \cdot \log (c)$ exists with a slope of $-2.3 R T /(2 F)$. For quasireversible reaction the dependence of $E_{\mathrm{p}}$ vs. $\log (c)$ is still linear but the slope is less than $-2.3 R T /(2 F)$, being dependent on the apparent reversibility of the reaction. Furthermore, care has to be taken by using the quasireversible maximum for estimation of the kinetics of Reaction II). It is generally known that the position of the quasireversible maximum is a function of the signal amplitude and the electron transfer coefficient [37]. In addition, the critical kinetic parameter $K_{\max }$ for Reaction II) depends on the concentration parameter obeying the following relationship:

$\log \left(K_{\max }\right)=-0.4589 \log (c)+0.1584$ which is valid for $E_{\mathrm{sw}}=20 \mathrm{mV}$ and $\alpha=0.5$. Note that the sensitivity of the quasireversible maximum on the concentration of the ligand, can also serve as a qualitative diagnostic criteria for recognition of Reaction II.

A representative SW voltammogram of Reaction III is depicted in Figure 1C. The overall shape of the response is considerably different compared to Reactions I and II. The narrow backward (anodic) component of Reaction III is a consequence of the adsorption of the reaction ligand. Besides of the kinetic parameter $\lambda$ and diffusion parameter $\gamma$, the response is likewise determined by the adsorption parameter $\rho=K_{\text {ads }} \sqrt{D} / \sqrt{f}$ reflecting the influence of the adsorption strength of the reacting ligand. The adsorption parameter influences both the peak potentials and peak currents of the dimensionless responses. Shown in Figure 2 is the dependence of dimensionless peak currents on the adsorption constant for different standard rate constants of Reaction III. Parabolic dependencies of $\Psi_{\mathrm{p}}$ vs. $\log \left(K_{\mathrm{ads}}\right)$ have been observed, with a maximum being shifted toward lower values of $K_{\text {ads }}$ by increasing the rate of the charge 


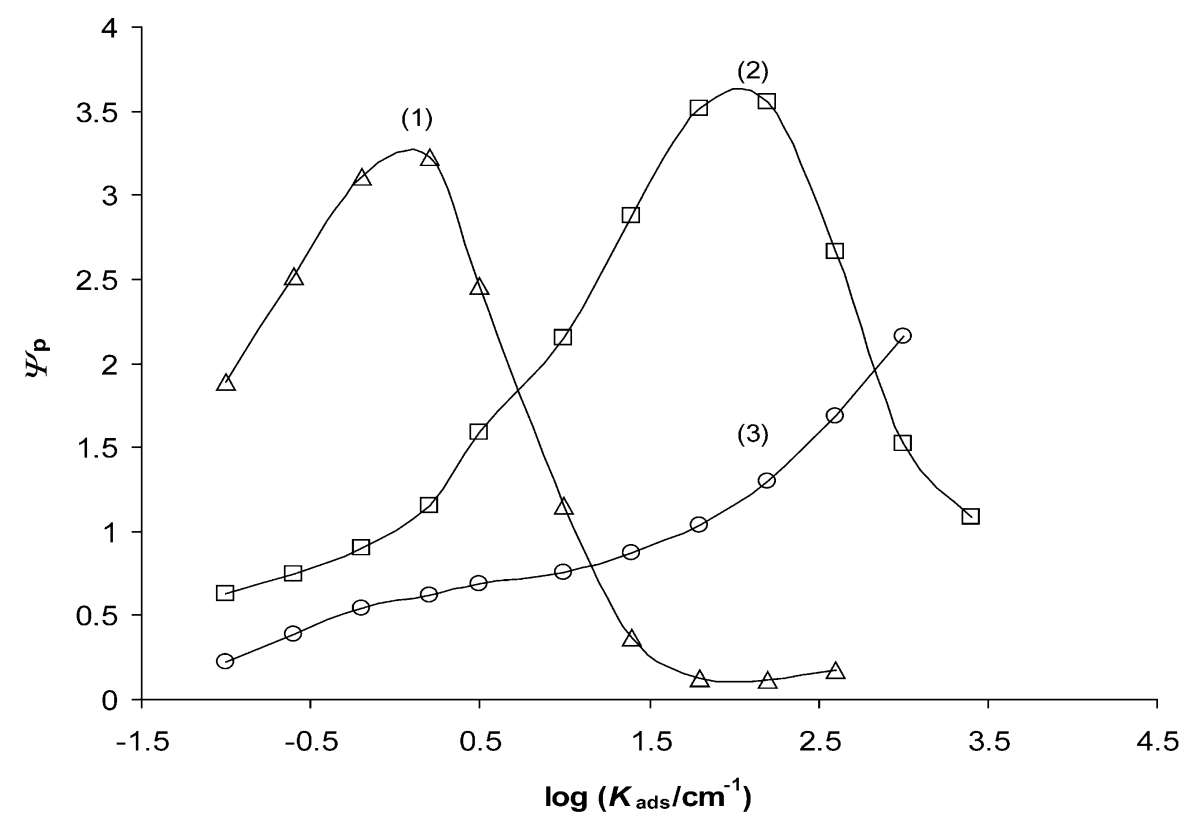

Fig. 2. Dependence of the dimensionless net peak current of Reaction III on the logarithm of the adsorption constant simulated for $k_{\mathrm{s}} / \mathrm{cm} \mathrm{s}^{-1}=1$ (1), 10 (2) and 100 (3). Other conditions were the same as in Figure 1C.

transfer. Interestingly, the moderate adsorption produces the highest peak current, which is of particular importance for analytical purposes. The parabolic dependence of the net peak current on the adsorption strength is a consequence of two opposite effects. On one side, the adsorption increases the amount of the deposited electroactive material, which leads to an increase of the peak current. On the other side, in the course of a single potential pulse, the current diminishes more rapidly as the adsorption strength of the redox couple increases. Under strong adsorption a less current remains to be measured at the end of the potential pulse, i.e., at the moment when the current is sampled in SWV.

Unlike the Reactions I and II, for a given adsorption parameter, the apparent reversibility of Reaction III depends on the kinetic parameter defined as a simple product of the parameters $\lambda$ and $\gamma$, i.e., $\omega=\lambda \gamma$, or $\omega=k_{\mathrm{s}} / f \tau_{\mathrm{s}}$. The quasireversible maximum is particularly pronounced in this mechanism, being represented by a sharp parabolic dependence of the dimensionless peak current versus the kinetic parameter $\omega$. However, an important property of the position of the quasireversible maximum of Reaction III is the dependence on the adsorption constant defined by the equation:

$\log \left(\omega_{\max }\right)=-0.5257 \log \left(K_{\mathrm{ads}}\right)+0.049$

which holds for $\alpha=0.5$ and $E_{\mathrm{sw}}=20 \mathrm{mV}$.

In addition of the quasireversible maximum, an inherent feature of Reaction III is the splitting of the net SW response under influence of the large signal amplitude [33-35]. The splitting of the net SW peak is a consequence of the large separation between the forward and backward component of the response that is predominantly controlled by the

Electroanalysis 2004, 16, No. 10 charge transfer kinetics and the strength of the ligand adsorption [33]. The splitting of the net peak could be explored for both qualitative recognition of the Reaction III and kinetic measurements. Hence, it is a concurrent method to the quasireversible maximum for estimation of the standard redox rate constant. Moreover, the splitting of the response appears within the narrow interval of the adsorption constant $\left(1<K_{\text {ads }} / \mathrm{cm}^{-1}<65\right)$, thus providing a basis for a rough evaluation of the strength of the adsorption of the reacting ligand.

Representative theoretical SW voltammogram of Reaction IV is shown in Figure 1D. This is the most complex cathodic stripping electrode mechanism unifying the properties of the Reactions II and III. The dimensionless response is controlled by all four parameters, i.e., the kinetic parameter $\lambda$, the diffusion parameter $\gamma$, the adsorption parameter $\rho$, and the concentration parameter $c$. At a given value of the concentration parameter, the apparent reversibility of Reaction IV is controlled by the complex kinetic parameter defined as $\chi=\lambda \rho$, or $\chi=k_{\mathrm{s}} K_{\text {ads }} / f$.

As shown in Figure 3, the dimensionless peak currents increases linearly by increasing the adsorption constant $K_{\text {ads }}$ (note that the strength of the adsorption depends inversely on the adsorption constant $K_{\text {ads }}$ ). It means the stronger the adsorption of the reacting ligand the lower the net SW peak. Thus, the strong ligand adsorption is undesirable for analytical purposes by this mechanism. Obviously, this feature differs from the corresponding one in the case of Reaction III, where the dimensionless peak current is a parabolic function of the adsorption constant (see Fig. 2). As can be expected, resembling Reaction II, the peak potential depends linearly on the ligand concentration with a slope equivalent as for Reaction II, i.e., $\Delta E_{\mathrm{p}} / \log (c)=$ 


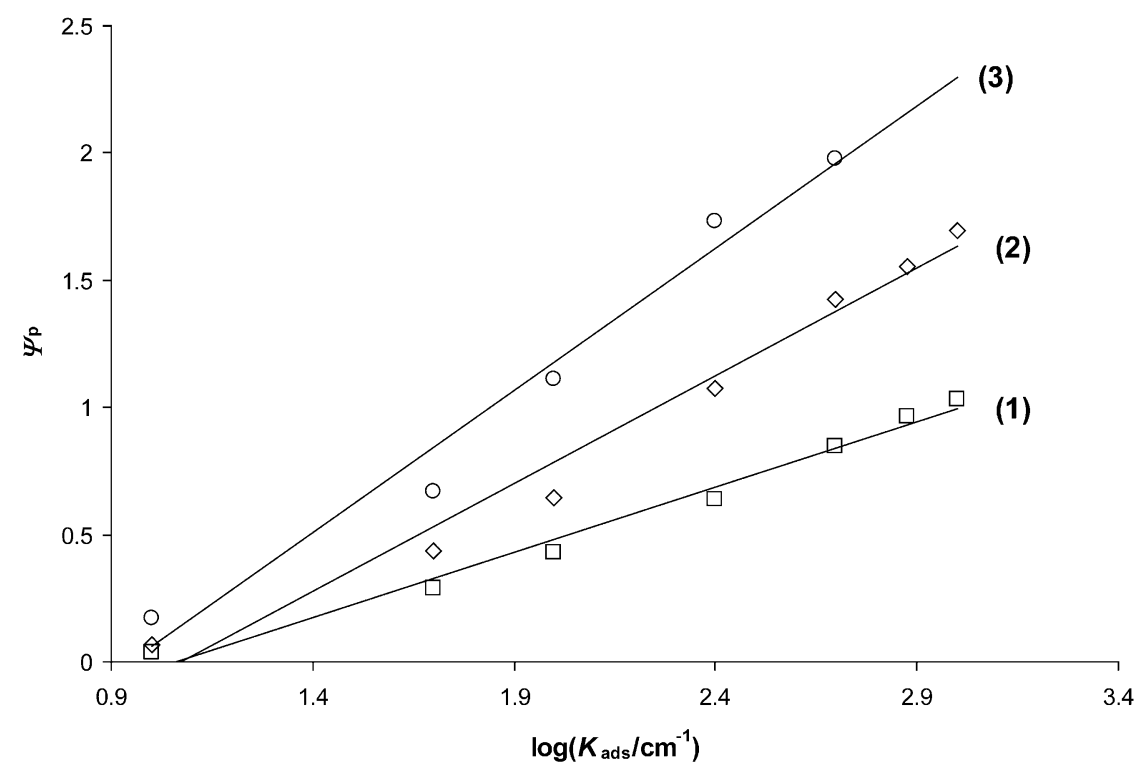

Fig. 3. Theoretical dependence of the dimensionless net peak current of Reaction IV on the logarithm of adsorption constant simulated for $c=0.1, E_{\mathrm{sw}}=20 \mathrm{mV}$, and $k_{\mathrm{s}} / \mathrm{cm} \mathrm{s}^{-1}=0.4$ (1), 1 (2) and 2.5 (3). The other conditions were the same as in Figure 1D.

$-2.3 R T / 2 F$, valid for reversible electrode reaction. Only the intercept of the line is dependent of the adsorption constant, which is not the case for Reaction II.

For Reaction IV, care has to be taken by using the quasireversible maximum for kinetic measurements. The critical kinetic parameters $\chi_{\max }$ is a function of the adsorption constant obeying the equation:

$\log \left(\chi_{\max }\right)=-0.0614 K_{\mathrm{ads}} / \mathrm{cm}^{-1}+0.441$

valid for $E_{\mathrm{sw}}=25 \mathrm{mV}, c=0.1$ and $\alpha=0.5$. Interestingly, although Reaction IV is of second order, the position of the quasireversible maximum is virtually independent on the concentration parameter, which was not the case for the simple second order Reaction II.

Resembling toReaction III, the response of Reaction IV is associated with the split SW peaks under large signal amplitude. Obviously, the splitting of the response is a feature of electrode reactions in which both components of the redox couple are immobilized on the electrode surface [38]. For Reaction IV, the splitting appears within a narrower range of values of the adsorption constant compared to the Reaction III, i.e., $10<K_{\text {ads }} / \mathrm{cm}^{-1}<40$. It is more important to emphasize that the potential separation between the split SW peaks depends on the concentration parameter $c$, which is a unique feature of Reaction IV. The effect of increasing the concentration parameter $c$ on the dimensionless response of Reaction IV under conditions of split net SW peak is shown in Figure 4. The increase of the concentration parameter $c$ is followed by an increase in the potential separation between the split SW peaks. For a certain minimal value of the concentration parameter the splitting disappears. This important behavior makes significant discrepancy between Reactions III and IV.

\section{Analytical Sensitivity}

The relationship between the real net peak current and the dimensionless net peak current $I_{\mathrm{p}}=\Psi_{\mathrm{p}} 2 F S c^{*}(L) \sqrt{D f}$ shows that the function $\Psi_{\mathrm{p}}$ is an amperometric constant determining the gradient of the increase of $I_{\mathrm{p}}$ with $c^{*}(\mathrm{~L})$, or in other words, the function $\Psi_{\mathrm{p}}$ determines the sensitivity of an analytical method. As demonstrated in the previous section, the diagnostic criteria for distinguishing particular cathodic stripping electrode mechanism, can be established by studying the properties of the dimensionless function $\Psi$. However, from analytical point of view it is particularly important to inspect the influence of the excitement signal parameters, i.e., SW frequency and SW amplitude, on the real peak current in order to select conditions that provide the highest analytical sensitivity.

Figure 5 shows the dependence of the normalized real peak current on the frequency for all four reactions. Over the frequency interval $10 \leq f / \mathrm{Hz} \leq 1000$, a linear dependence is observed only for Reactions I and II. In the presence of adsorption, i.e., Reactions III and IV, complex nonlinear dependencies have been found, particularly at lower frequencies $(f<100 \mathrm{~Hz})$. This behavior is a consequence of the fact that the variation of the frequency affects simultaneously both the kinetic parameter $\lambda$ and the adsorption parameter $\rho$, resulting in a complex behavior of the real net peak current. Nevertheless, as a criterion for selecting an optimal response for analytical purposes it will serve as the maximum of the ratio $I_{\mathrm{p}} / \Delta E_{\mathrm{p} / 2}$, where $\Delta E_{\mathrm{p} / 2}$ is the half-peak width. For reaction I and II the ratio $I_{\mathrm{p}} / \Delta E_{\mathrm{p} / 2}$ increases linearly with $f$, whereas for reactions III and IV, the ratio reaches a maximum for the same frequency corresponding to the position of the quasireversible maximum (results not shown). Therefore, the critical frequency $f_{\max }$, 

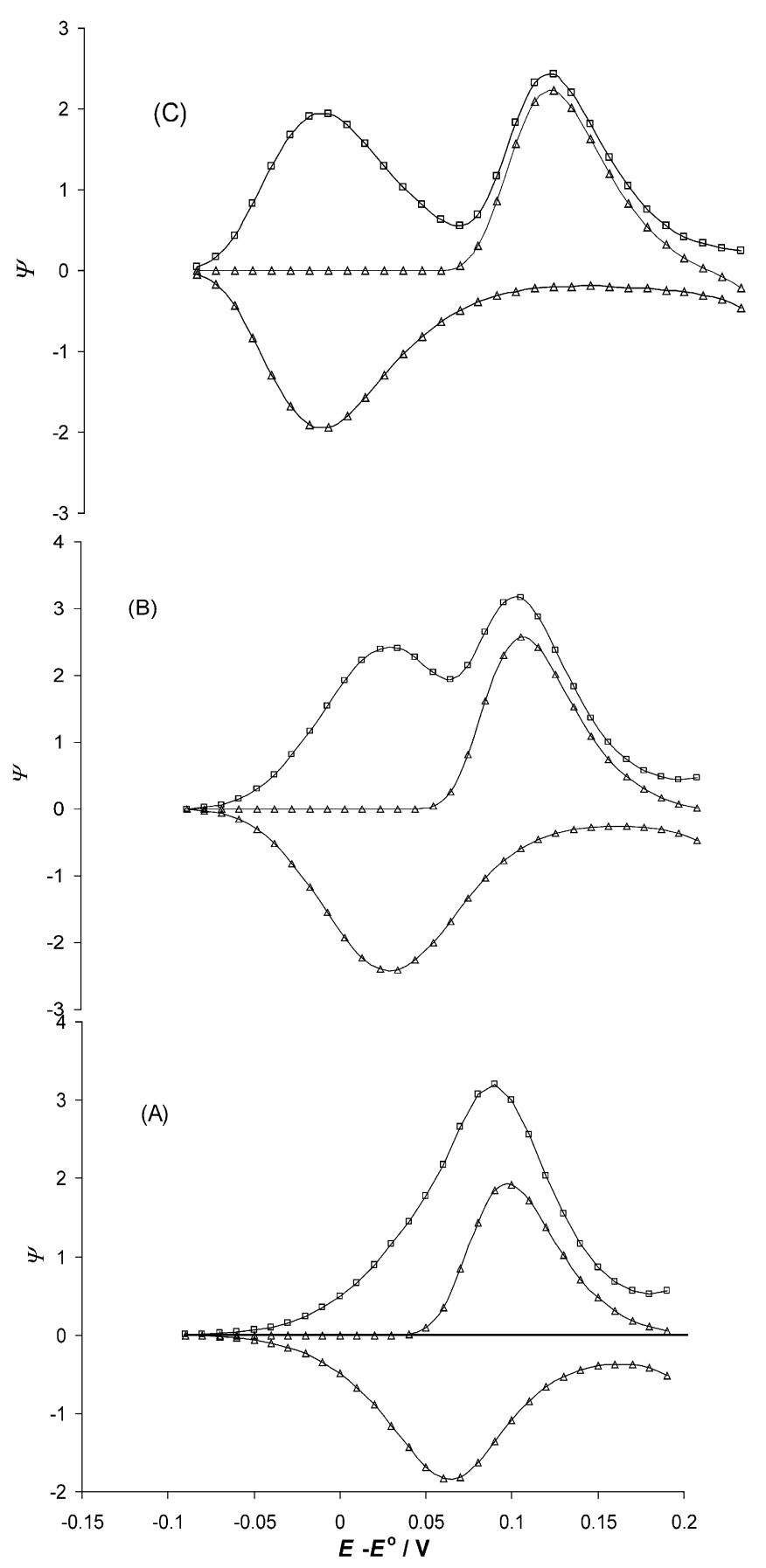

Fig. 4. Influence of the ligand concentration on the theoretical split SW peaks of Reaction IV: The conditions of the simulations were: $k_{\mathrm{s}}=100 \mathrm{~cm} \mathrm{~s}^{-1}, \alpha=0.5, K_{\mathrm{ads}}=10 \mathrm{~cm}^{-1}, E_{\mathrm{acc}}=0.2 \mathrm{~V}, t_{\mathrm{acc}}=$ $0.1 \mathrm{~s}, f=\mathrm{Hz}, E_{\mathrm{sw}}=80 \mathrm{mV}, \mathrm{d} E=10 \mathrm{mV}$, and $c=0.001$ (A), 0.01 (B), and $0.1(\mathrm{C})$.

serving for estimation of the standard rate constant, is also the best choice for analytical purposes.

Generally speaking, the SW amplitude affects all the properties of the response. Figure 6 depicts the variation of the ratio $I_{\mathrm{p}} / \Delta E_{\mathrm{p} / 2}$ with the $\mathrm{SW}$ amplitude for all mechanisms. All the dependencies are parabolic. The position of the

Electroanalysis 2004, 16, No. 10 maximum indicates the optimal amplitude for analytical purposes. Special care has to be taken concerning with the split SW peaks which are attributed to Reactions III and IV. Although this phenomenon is particularly useful for qualitative recognition and kinetic measurements it is a completely undesirable phenomenon from analytical point of view.

\section{Experimental Results}

\subsection{General Voltammetric Behavior of Uracil Derivatives}

Figure 7 shows typical SW cathodic stripping voltammograms of 2-thiouracil (TU), 5-azauracil (AzaU), 5-fluorouracil (FU), and 6-propyl-2-thiouracil (PTU). The order of the cathodic stripping reaction can be established by simple analysis of the peak potential of the SW response as a function of the concentration of the reacting compound. The peak potential of the net SW response of both TU and FU is insensitive on the concentration of the respective compound. Therefore, these two compounds belong to either Reaction I or Reaction III. On the base of the shape of the response one easily recognize that $\mathrm{TU}$ reacts according to the Reaction I (compare the response of TU with the theoretical response presented in Fig. 1A) and FU according to Reaction III (compare the response of FU with the theoretical response in Fig. 1C). Furthermore, the presence of the adsorption of the reaction ligand can be revealed by inspecting the influence of the deposition undertaken at more negative potential than the peak potential of the net $\mathrm{SW}$ response. It has been established that the accumulation time at potential $E_{\text {acc }} \leq-0.200 \mathrm{~V}$ has no influence on either the peak potential or peak current of the net SW response of TU. On contrary, in the case of FU, the increase of the accumulation time at $E_{\text {acc }}=-0.200 \mathrm{~V}$ leads to proportional increase of all three components of the SW response. Therefore, the electrode reaction of TU occurs according to the mechanism I and that of FU is ascribed to the mechanism III.

The increase of the concentration of both AzaU and PTU caused a shift of the peak potential of the net response towards more negative potentials. The slope of the dependence $E_{\mathrm{p}}$ vs. $\log \left(c^{*}(\mathrm{~L})\right)$ is -26 and $-45 \mathrm{mV}$ for AzaU and PTU, respectively, revealing that the cathodic stripping reactions of these compounds are of second order. Inspecting the influence of the accumulation at more negative potential than the net peak potential, it was easily shown that the reaction of AzaU belongs to the Reaction II and that of PTU to the complex Reaction mechanism IV. Recently it has been demonstrated that the strength of adsorption of PTU could be varied in the presence of acetonitrile due to the concurrent adsorption [34]. Increasing the amount of acetonitrile caused the decrease of the PTU adsorption strength, which was manifested by linear increase of the net SW peak current and a proportional shift of the peak potential with a slope of $\Delta E_{\mathrm{p}} / \varphi(\mathrm{AN})=-27 \mathrm{mV}$ $(\varphi(\mathrm{AN})$ is the volumic parts of acetonitrile in the electrolyte 


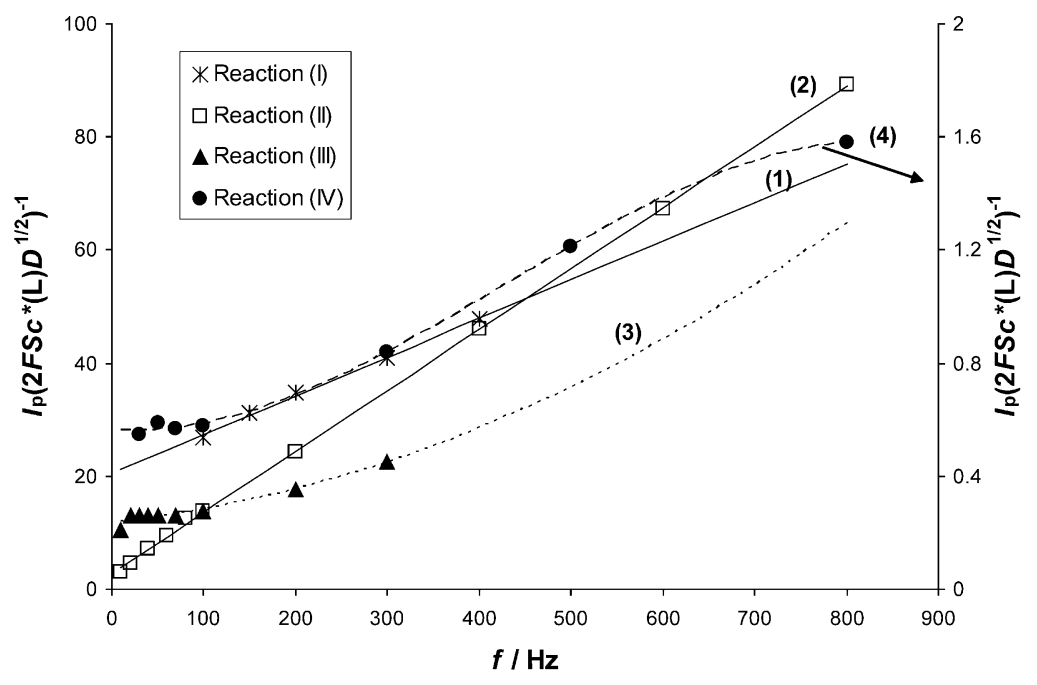

Fig. 5. Dependence of the normalized real net peak current $I_{\mathrm{p}} / 2 F S c^{*}(L) \sqrt{D}$. on the SW frequency for Reaction I (1), II (2), III (3), and IV (4). The conditions of the simulations were: $t_{\mathrm{acc}}=0.1 \mathrm{~s}, E_{\mathrm{acc}}=0.1 \mathrm{~V}, \mathrm{~d} E=10 \mathrm{mV}, \alpha=0.5$ (valid for all reactions), $E_{\mathrm{sw}}=30 \mathrm{mV}$, $k_{\mathrm{s}}=0.5 \mathrm{~cm} \mathrm{~s}^{-1}$ (for Reaction I), $E_{\mathrm{sw}}=50 \mathrm{mV}, k_{\mathrm{s}}=0.6 \mathrm{~cm} \mathrm{~s}^{-1}, c=0.01$ (for Reaction II), $E_{\mathrm{sw}}=25 \mathrm{mV}, k_{\mathrm{s}}=3.16 \mathrm{~cm} \mathrm{~s}^{-1}$, and $K_{\mathrm{ads}}=10 \mathrm{~cm}^{-1}$ (for Reaction III), and $E_{\mathrm{sw}}=50 \mathrm{mV}, k_{\mathrm{s}}=0.2 \mathrm{~cm} \mathrm{~s}^{-1}, K_{\mathrm{ads}}=1 \mathrm{~cm}^{-1}$ and $c=0.01$ (for Reaction IV).

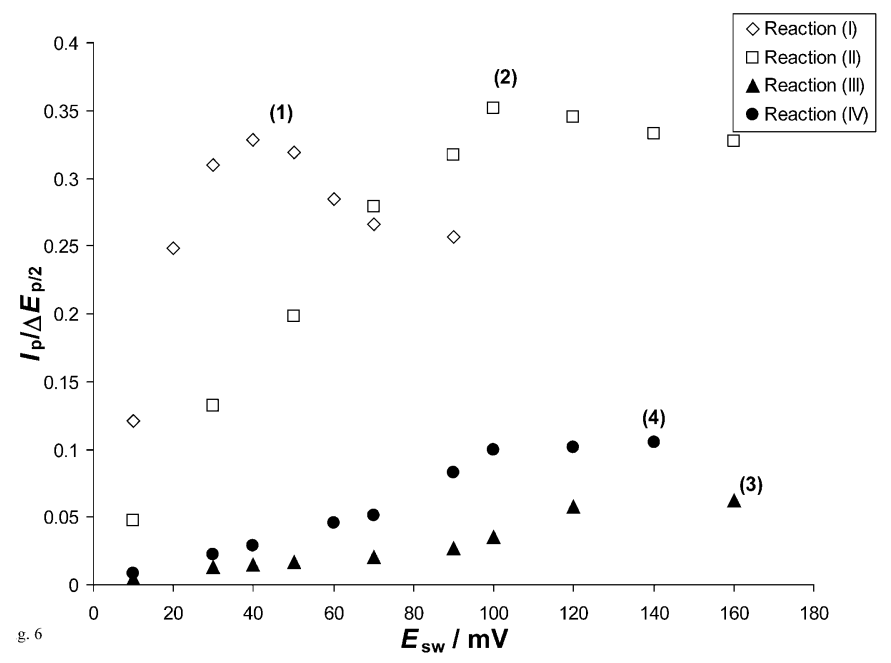

Fig. 6. The dependence of the ratio $I_{\mathrm{p}} / \Delta E_{\mathrm{p} / 2}\left(\Delta E_{\mathrm{p} / 2}\right.$ is the halfpeak width) on the SW amplitude for Reaction I (curve 1), Reaction II (curve 2), Reaction III (curve 3), and Reaction IV (curve 4). The conditions of the simulations were: $k_{\mathrm{s}}=0.5 \mathrm{~cm} \mathrm{~s}^{-1}$, $f=50 \mathrm{~Hz}$ (for reaction I), $k_{\mathrm{s}}=0.9 \mathrm{~cm} \mathrm{~s}^{-1}, f=100 \mathrm{~Hz}, c=0.01$ (for Reaction II), $f=100 \mathrm{~Hz}, k_{\mathrm{s}}=0.316 \mathrm{~cm} \mathrm{~s}^{-1}, K_{\mathrm{ads}}=10 \mathrm{~cm}^{-1}$ (for reaction III), and $k_{\mathrm{s}}=0.316 \mathrm{~cm} \mathrm{~s}^{-1}, K_{\mathrm{ads}}=10 \mathrm{~cm}^{-1}, c=0.1$, and $f=10 \mathrm{~Hz}$ (for Reaction IV). Other conditions were the same as those for the Figure 5.

solution). Therefore, the behavior of PTU fully obeys the theoretical predictions regarding Reaction IV.

\subsection{Kinetic Measurements}

As predicted by the theory, the quasireversible maximum is an inherent property attributing to all cathodic stripping reactions. It can be exploited for kinetic measurements applying a simple experimental methodology. In the experimental analysis, the quasireversible maximum can be demonstrated by varying the SW frequency and by plotting the ratio $I_{\mathrm{p}} / \sqrt{f}$ versus $1 / f^{/ 4}$ for Reactions I and II, or $I_{\mathrm{p}} / \sqrt{f}$ versus $I_{\mathrm{p}} / f$ for Reactions III and IV. The ratio $I_{\mathrm{p}} / \sqrt{f}$ corresponds to the dimensionless peak current and the quantity $1 / f^{3 / 4}$ corresponds to the crucial kinetic parameter $K=k_{\mathrm{s}} / D^{1 / 4} f^{3 / 4} \sqrt{r_{s}}$ controlling the apparent reversibility of both Reactions I and II. Whereas the ratio $1 / f$ corresponds to the kinetic parameter $\omega=k_{\mathrm{s}} / f \tau_{\mathrm{s}}$ (for Reaction III) and the parameter $\chi=k_{\mathrm{s}} K_{\text {ads }} / f$ (for Reaction IV). Measuring experimentally the critical frequency $f_{\max }$, associated with the position of the quasireversible maximum, the standard rate constant could be estimated according to the following formulae:
$k_{s}=K_{\max } D^{1 / 4} f^{3 / 4} \sqrt{r_{s}}$
(5) (for Reaction I and II)
$k_{s}=\omega_{\max } f_{\max } r_{s}$
(6) (for Reaction III)
$k_{s}=\chi_{\max } f_{\max } / K_{a d s}$
(7) (for Reaction IV)

In the case of TU, the critical frequency was $f_{\max }=125 \mathrm{~Hz}$ for an amplitude of $E_{\mathrm{sw}}=20 \mathrm{mV}$. According to the theoretical predictions, the value of the critical kinetic parameter for $E_{\mathrm{sw}}=20 \mathrm{mV}$ and $\alpha=0.5$ is $K_{\max }=1.14$. Applying Equation 5 , the standard rate constant estimates $k_{\mathrm{s}}=2.015 \mathrm{~cm} \mathrm{~s}^{-1}$. For this calculation the diffusion coefficient was assumed to be $D=5 \times 10^{-6} \mathrm{~cm}^{2} \mathrm{~s}^{-1}$. Applying the same procedure for an amplitude of $E_{\mathrm{sw}}=40 \mathrm{mV}$, the value $k_{\mathrm{s}}=1.66 \mathrm{~cm} \mathrm{~s}^{-1}$ was assessed. It is worth noting that the precision of the kinetic measurements based on quasireversible maximum involves an error of about $10 \%$ [37].

Figure 8 shows the quasireversible maximums of AzaU measured for three different concentrations. As predicted 

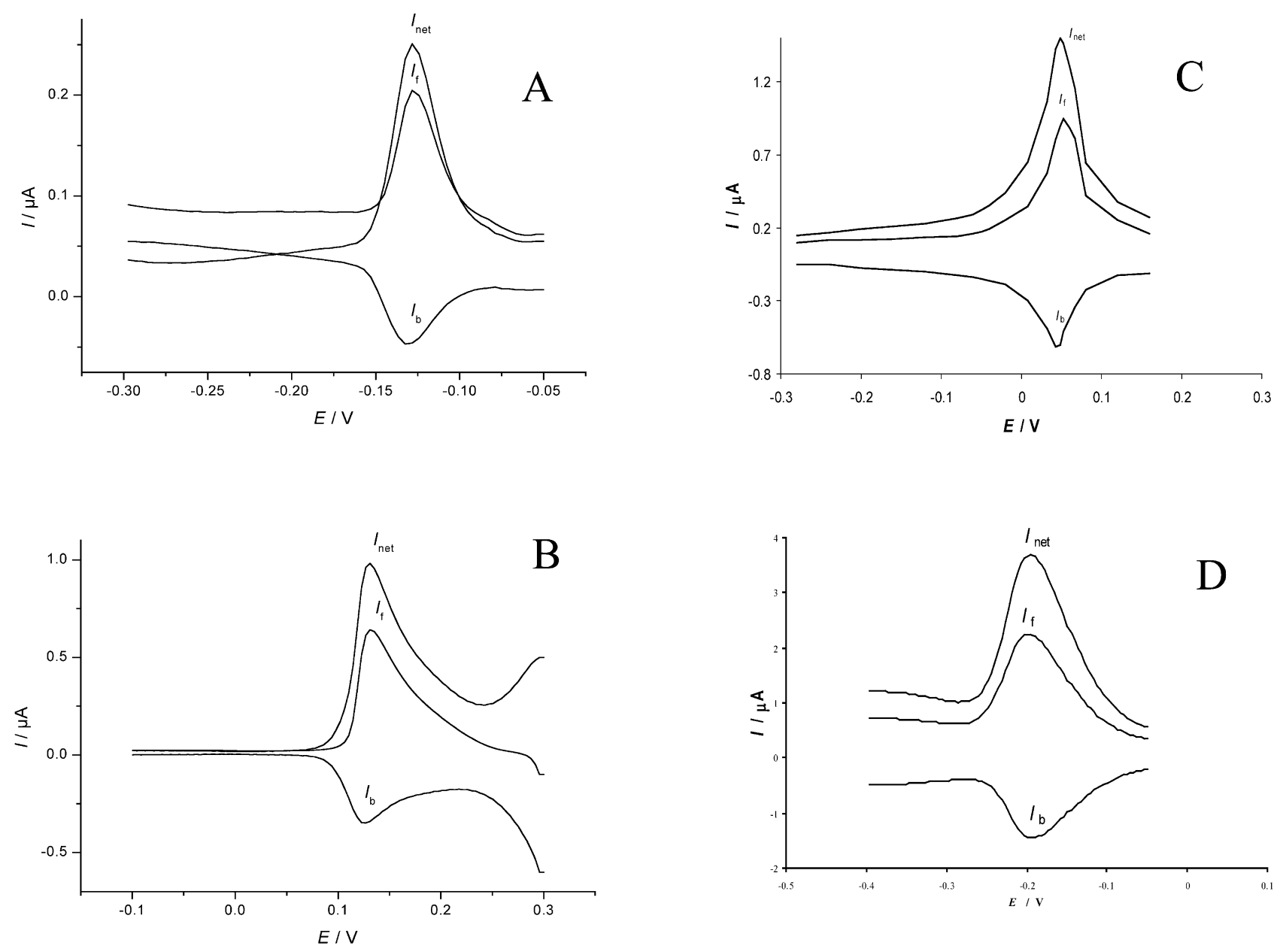

Fig. 7. A) SW voltammogram of $1 \times 10^{-5} \mathrm{~mol} \mathrm{dm}^{-3} 2$-thiouracil (TU) recorded in $0.1 \mathrm{~mol} \mathrm{dm}^{-3} \mathrm{HCl}$ solution, $E_{\mathrm{acc}}=0.0 \mathrm{~V}, t_{\mathrm{acc}}=45 \mathrm{~s}, E_{\mathrm{sw}}$ $=25 \mathrm{mV}, \mathrm{d} E=2 \mathrm{mV}$, and $f=150 \mathrm{~Hz}$. B) SW voltammogram of $5 \times 10^{-6} \mathrm{~mol} \mathrm{dm}^{-3}$ solution of 5-azauracil (AzaU) recorded in $1 \mathrm{~mol} \mathrm{dm}^{-3}$ $\mathrm{KNO}_{3}, t_{\mathrm{acc}}=30 \mathrm{~s}, E_{\mathrm{acc}}=0.3 \mathrm{~V}, f=100 \mathrm{~Hz}, E_{\mathrm{sw}}=25 \mathrm{mV}, \mathrm{d} E=2 \mathrm{mV}$. C) SW voltammogram of $1 \times 10^{-6} \mathrm{~mol} \mathrm{dm}^{-3} 5$-fluorouracil (FU) in $0.1 \mathrm{~mol} \mathrm{dm}^{-3}$ sodium sulfate $(\mathrm{pH}=6.7), E_{\mathrm{acc}}=0.2 \mathrm{~V}, t_{\mathrm{acc}}=15 \mathrm{~s}, \mathrm{~d} E=2 \mathrm{mV}, E_{\mathrm{sw}}=20 \mathrm{mV}, f=100 \mathrm{~Hz}$. D) SW voltammogram of $4 \times 10^{-6}$ mol dm ${ }^{-3} 6$-propyl-2-thiouracil (PTU) recorded in $1 \mathrm{~mol} \mathrm{dm}^{-3} \mathrm{KNO}_{3}, t_{\mathrm{acc}}=30 \mathrm{~s}, E_{\mathrm{acc}}=-0.1 \mathrm{~V}, f=150 \mathrm{~Hz}, E_{\mathrm{sw}}=25 \mathrm{mV}$, and dE= $4 \mathrm{mV}$. The Symbols $I_{\mathrm{f}}, I_{\mathrm{b}}$, and $I_{\text {net }}$ denote the forward, backward and net current, respectively.

by Equation 2 the position of the quasireversible maximum is sensitive to the concentration of the reacting ligand. This is the first experimental verification of this important property of the cathodic stripping reaction of second order. The calculated standard rate constant of AzaU according to Equation 5 is $k_{\mathrm{s}}=0.025 \mathrm{~cm} \mathrm{~s}^{-1}$, assuming $\alpha=0.5$ and $D=$ $5 \times 10^{-6} \mathrm{~cm}^{2} \mathrm{~s}^{-1}$.

As predicted by the theory, the cathodic stripping reaction coupled by adsorption of the reacting ligand is attributed with the split net SW peak under certain conditions. The splitting of the response was observed for both FU and PTU, confirming the adsorption of these compounds. The splitting of the response is a particularly important property since it enables a complete characterization of the electrode reaction including the knowledge of the adsorption constant, electron transfer coefficient, standard rate constant as well as the precise measurement of the formal potential of the system [38]. Utilizing the procedure described in [35], the adsorption constant and the electron transfer coefficient of FU estimate $K_{\text {ads }}=10 \mathrm{~cm}^{-1}$ and $\alpha=0.54$. Knowing these values, the critical kinetic parameter is $\omega_{\max }=0.24$ (calculated for an amplitude $E_{\mathrm{sw}}=25 \mathrm{mV}$ ). The quasireversible maximum was measured for several FU concentration over the interval $10^{-7} \leq c(\mathrm{FU}) / \mathrm{mol} \mathrm{dm}{ }^{-3} \leq 10^{-5}$. The position of the quasireversible maximum was independent of the concentration associated with a single critical frequency of $f_{\max }=400 \mathrm{~Hz}$. Thus, the standard rate constant, estimated according to Equation 6 is $k_{\mathrm{s}}=96 \mathrm{~cm} \mathrm{~s}^{-1}$, which is close to the value of $k_{\mathrm{s}}=54 \mathrm{~cm} \mathrm{~s}^{-1}$ estimated on the bases of the splitting of the net SW peak [35].

The kinetic parameters of PTU have been estimated applying an analogous procedure as that for FU yielding the following values: $K_{\mathrm{ads}}=10 \mathrm{~cm}^{-1}, k_{\mathrm{s}}=25 \mathrm{~cm} \mathrm{~s}^{-1}$, and the electron transfer coefficient $\alpha=0.6$ [33]. It is important to emphasize that the position of the quasireversible maximum measured for three different concentrations, ranged be- 


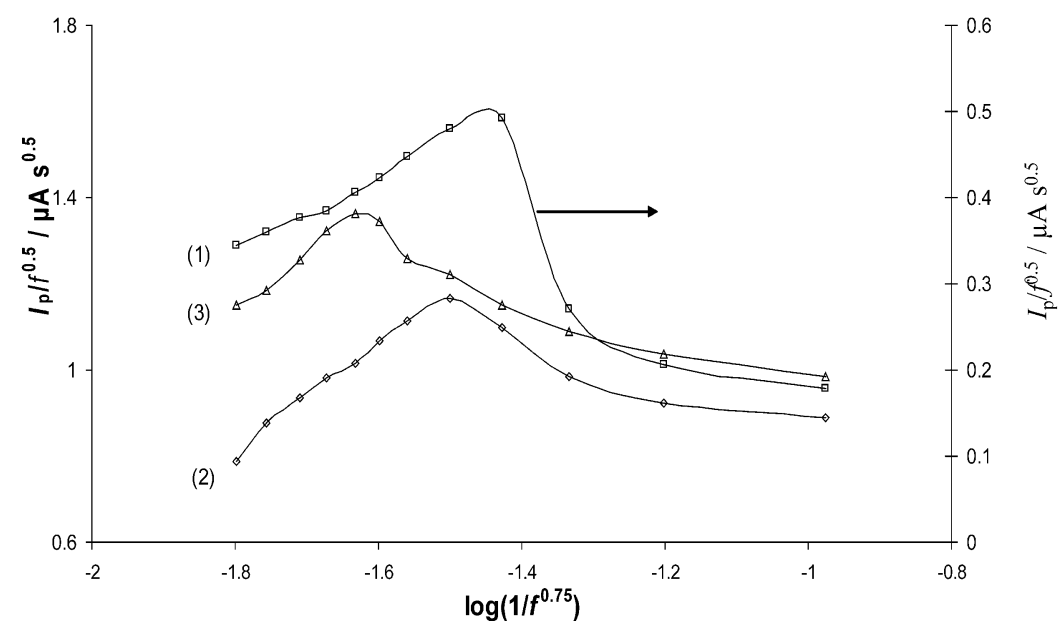

Fig. 8. Influence of the concentration of AzaU on the position of the quasireversible maximum. The concentrations of AzaU were: $c(\mathrm{AzaU}) / \mathrm{mol} \mathrm{dm}^{-3}=5 \times 10^{-6}(1), 5 \times 10^{-5}(2)$, and $5 \times 10^{-4}(3)$. For the other conditions see the caption of the Figure $7 \mathrm{~B}$.

tween $1 \times 10^{-7} \leq c(\mathrm{PTU}) / \mathrm{mol} \mathrm{dm}{ }^{-3} \leq 1 \times 10^{-5}$, was associated with the single critical frequency of $f_{\max }=150 \mathrm{~Hz}$. Thus, the position of the quasireversible maximum of the second order reaction coupled by adsorption of the ligand is insensitive to the concentration of the ligand, which is in accord to the theoretical findings. According to this procedure, the estimated value of the standard rate constant was $k_{\mathrm{s}}=10 \mathrm{~cm} \mathrm{~s}^{-1}$. Recalling that for the second order reaction of a dissolved ligand the position of the quasireversible maximum varies with the concentration of the ligand which was confirmed by the experiments with AzaU.

Finally, it is worth to point out that an alternative way for measuring the kinetics of such redox reactions one can find in the papers of Baranski et al [39, 40]. Our proposed mechanisms are compatible with the concept of electrosorption reactions used by the former authors [37]. It should be also noted that a comparative study for measuring the kinetics by square-wave and cyclic voltammetry of similar type of reactions is presented in the work of KomorskyLovric [41]. However, since the theory for cathodic stripping reactions in cyclic voltammetry is still not developed enough, the square-wave voltammetry is the best tool for measuring the kinetics of this kind of redox reactions.

\subsection{Analytical Application}

As recommended in Section 5, the criterion for selecting an optimal response for analytical application is the maximum of the quantity $I_{\mathrm{p}} / \Delta E_{\mathrm{p} / 2}$, which can be accomplished by adjusting the SW frequency and amplitude. Table 2 summarizes the optimal conditions for quantitative determination of the studied uracile derivatives applying cathodic stripping SW voltammetry. The detection limit was estimated according to the formula: $\Delta I_{\min }=\Delta I_{\mathrm{b}}+k S_{\mathrm{b}}$, where $\Delta I_{\mathrm{b}}$ is an average value of the supporting electrolyte currents, $k$ is a confidence level factor (for this calculation $k=3$, which means that the confidence level is $99.6 \%$ ) and $S_{\mathrm{b}}$ is a standard deviation of the blank current values. The accumulation has been carried out in quiet electrolyte solution. The determination of FU has been carried out in the presence of $\mathrm{Cu}^{2+}$ ions that enabled development of particularly sensitive method. The other details of the procedure can be found elsewhere [35].

\section{Acknowledgements}

Rubin Gulaboski thanks Deutsche Akademische Austauschdienst (DAAD) for providing of a PhD scholarship, and Valentin Mirceski thanks Alexander von Humboldt Stiftung for providing a Return Research Fellowship. Both authors kindly acknowledge the financial support of the Ministry of Science and Education of the Republic of Macedonia.

Table 2. Conditions for quantitative determination of uracil derivatives.

\begin{tabular}{lllcrll}
\hline Compound & $\begin{array}{l}\text { SW } \\
\text { frequency }(\mathrm{Hz})\end{array}$ & $\begin{array}{l}\text { SW } \\
\text { amplitude }(\mathrm{mV})\end{array}$ & $t_{\text {acc }}(\mathrm{s})$ & $E_{\text {acc }}(\mathrm{V})$ & $\begin{array}{l}\text { Concentration } \\
\text { range }\left(\mathrm{mol} \mathrm{dm}^{-3}\right)\end{array}$ & $\begin{array}{l}\text { Detection limit } \\
\left(\mathrm{mol} \mathrm{dm}^{-3}\right)\end{array}$ \\
\hline TU & 150 & 50 & 60 & 0.00 & $1 \times 10^{-7}-2 \times 10^{-5}$ & $2.0 \times 10^{-8}$ \\
AzaU & 120 & 60 & 45 & 0.30 & $1 \times 10^{-6}-5 \times 10^{-5}$ & $4.0 \times 10^{-7}$ \\
FU [35] & 120 & 20 & 180 & -0.30 & $1 \times 10^{-11}-5 \times 10^{-9}$ & $7.7 \times 10^{-12}$ \\
PTU & 150 & 40 & 120 & 0.20 & $5 \times 10^{-8}-2 \times 10^{-6}$ & $8.0 \times 10^{-9}$ \\
\hline
\end{tabular}




\section{References}

[1] Kh. Z. Brainina, Talanta, 1971, 18, 513.

[2] J. Wang, Stripping Analysis VCH, Deerfield Beach 1985, p. 54.

[3] T. M. Florence, J. Electroanal. Chem. 1979, 97, 219.

[4] R. D. Armstrong, D. F. Porter, H. R. Thirsk, J. Electroanal. Chem. 1967, 14, 17; J. Phys. Chem. 1968, 72, 2300.

[5] K. Shimizu, K. Aoki, R. A. Osteryoung, J. Electroanal. Chem. 1981, 129, 159.

[6] K. Shimizu, K. Aoki, R. A. Osteryoung, J. Electroanal. Chem. 1981, 129, 171.

[7] C. Harlyk, O. Nieto, G. Bordin, A. R. Rodriguez, J. Electroanal. Chem. 1998, 458, 199.

[8] M. Dabrio, A. R. Rodriguez, Anal. Chim. Acta 1999, 385, 295.

[9] J. G. Osteryoung, J. J. O'Dea in Electroanalytical Chemistry, Vol. XIV (Ed: A. J. Bard), Marcel Dekker, New York 1968, p. 209.

[10] M Lovric, in Electroanalytical Methods. Guide to Experiments and Applications (Ed. F. Scholz) Springer, Berlin 2002, p. 111.

[11] M. Lovric, I. Pizeta, Š. Komorsky-Lovric, Electroanalysis $1992,4,327$.

[12] V. Mirceski, M. Lovric, Electroanalysis 1998, 10, 975.

[13] K. Manandhar, D. Pletcher, Talanta 1977, 24, 387.

[14] R. G. Ball, D. L. Manning, O. Menis, Anal. Chem. 1960, 32, 621.

[15] W. Kemula, Z. Kublik, J. Tarazcewska, J. Microchem. Techniques 1962, 865.

[16] R. C. Propst, Anal. Chem. 1977, 49, 1199.

[17] Kh. Z. Brainina, E. M. Roizenblat, Zavodsk. Lab. 1962, 28, 21; Zh. Analit. Khim. 1964, 19, 681.

[18] H. Berge, P. Jeroschewski, Z. Anal. Chem. 1965, 207, 110; 1965, 212, 278; 1967, 228, 9; 1967, 230, 259.

[19] R. von Wandruszka, X. Yuan, M. J. Morra, Talanta 1993, 40, 37.
[20] M. J. Brand, B. Fleet, Analyst 1968, 93, 498; 1970, 95, 905.

[21] M. T. Stankovich, A. J. Bard, J. Electroanal. Chem. 1977, 75, 487.

[22] D. A. Csejka, S. T. Nakos, E. W. DuBord, Anal. Chem. 1975, $47,322$.

[23] R. A. Grier, R. W. Andreus, Anal. Chim. Acta 1981, 124, 333.

[24] V. Forsman, Anal. Chim. Acta 1983, 146, 71.

[25] J. M. Lopez Fonseca, A. Otero, J. Garcia Monteagudo, Talanta, 1988, 35, 7.

[26] I. E. Davidson, W. F. Smyth, Anal. Chim. Acta 1983, 147, 53.

[27] M. Heyrovsky, P. Mader, V. Vesela, M. Fedurco, J. Electroanal. Chem. 1994, 369, 53.

[28] M. Heyrovsky, S. Vavricka, J. Electroanal. Chem. 1997, 423, 125.

[29] J. M. Sevilla, T. Pineda, R. Madueno, A. J. Roman, M. Blazquez, J. Electroanal. Chem. 1998, 442, 107.

[30] W. Jin, Li Xiao, J. Electroanal. Chem. 1997, 434, 37.

[31] M. Wrona, Bioelectrochem. Bioenerg. 1983, 10, 169.

[32] Z. Ahmed, M. Ahmed, M. Ibrahim, M. Kamal, Y. Temerk, Talanta 1994, 41, 659.

[33] V. Mirceski, M. Lovric, Anal. Chim. Acta 1999, 386, 47.

[34] R. Gulaboski, V. Mirceski, Š. Komorsky-Lovric, Electroanalysis 2002, 14, 345.

[35] V. Mirceski, R. Gulaboski, B. Jordanoski, Š. KomorskyLovric, J. Electroanal. Chem. 2000, 490, 37.

[36] R. S. Nicholson, M. L. Olmstead, in: Electrochemistry: Calculations, Simulation and Instrumentation, Vol. 2 (Eds. J. S. Mattson, H. B. Mark, H. C. MacDonald ), Marcel Dekker New York 1972.

[37] V. Mirceski, M. Lovric, Electroanalysis 1999, 11, 984.

[38] V. Mirceski, M. Lovric, Electroanalyis 1997, 9, 1283.

[39] A. Szulborksa, A. Baranski, J. Electroanal. Chem. 1994, 37, 269.

[40] A. R. Harman, A. S. Baranski, Anal. Chem. 1991, 63, 1158.

[41] Š. Komorsky-Lovric, Fresenius J. Anal. Chem. 1996, 356, 306. 